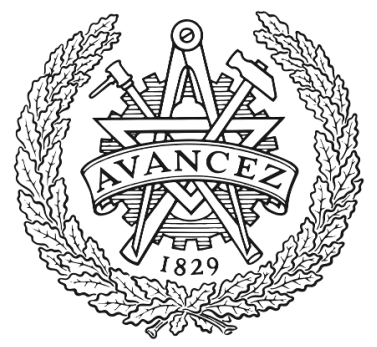

CHALMERS

UNIVERSITY OF TECHNOLOGY

\title{
Electroassisted Filtration of Microfibrillated Cellulose: Insights Gained from Experimental and Simulation Studies
}

Downloaded from: https://research.chalmers.se, 2023-04-26 13:15 UTC

Citation for the original published paper (version of record):

Karna, N., Lidén, A., Wohlert, J. et al (2021). Electroassisted Filtration of Microfibrillated Cellulose: Insights Gained from Experimental and

Simulation Studies. Industrial \& Engineering Chemistry Research, 60(48): 17663-17676.

http://dx.doi.org/10.1021/acs.iecr.1c03749

N.B. When citing this work, cite the original published paper. 


\title{
Electroassisted Filtration of Microfibrillated Cellulose: Insights Gained from Experimental and Simulation Studies
}

\author{
Nabin Kumar Karna, Anna Lidén, Jakob Wohlert, and Hans Theliander* \\ Cite This: Ind. Eng. Chem. Res. 2021, 60, 17663-17676 \\ Read Online
}

ABSTRACT: An electroassisted filtration technique has been employed to improve dewatering of a suspension of microfibrillated cellulose (MFC) produced via 2,2,6,6-tetramethylpiperidinyl-1-oxyl (TEMPO)-mediated oxidation. In addition, all-atom molecular dynamic (MD) simulations were performed to deepen the understanding of the complicated dewatering mechanism on a molecular level. Both the experimental and the simulation results implied that the dewatering rate was not only improved when electroassisted filtration was used but also found to be proportional Electro-assisted filtration of TEMPO-oxidized microfibrillated cellulose to the strength of the electric field. A channeled dewatered structure was observed for these experiments and may have contributed to enhanced dewatering by providing high overall permeability. The MD simulations revealed that the electric field had a significant impact on the fibril movement, whereas the impact of pressure was limited. The simulations also suggested that the increased filtrate flow upon the application of an electric field was not only due to electroosmotic flow but also due to electrophoretic movement of the fibrils toward the anode that led to the release of water that had been trapped between the fibrils, allowing it to be pressed out together with the rest of the bulk water. This study shows that electroassisted filtration has the potential to improve the dewatering of TEMPO-MFC, and the MD simulations provide further insights into the dewatering mechanism.

\section{INTRODUCTION}

Cellulose, a biopolymer built up of glucose monomers, is of great importance in today's society. It is currently used in applications such as paper and board products, textiles, and specialty chemicals (e.g., carboxymethyl cellulose). Furthermore, cellulose is presented as an excellent candidate in the industrial transition from using finite to renewable resources: its potential reaches far beyond its current applications.

In plants, the cellulose polymer is found in the wall of various cell structures as bundles of cellulose fibrils formed by stacks of cellulose polymers. This hierarchical structure allows cellulose to be used in a variety of applications: from a cellulose fiber (micrometer scale) down to single cellulose chains (nanometer scale). So far, the cell/fiber structure has been used in the production of paper and board and the polymeric structure has been used for textiles and specialty chemicals. However, the intermediate structures have not been used as extensively on a large industrial scale. One of these intermediate structures is microfibrillated cellulose (MFC), which is liberated from bundles of cellulose fibers by mechanical means. ${ }^{1}$ This type of structure has a number of interesting properties, including a high surface area with the potential for modifications and good mechanical properties. A great deal of research has focused on understanding the properties $^{2-5}$ and applications ${ }^{6-8}$ of MFC since the pioneering work of Herrick et al. ${ }^{9}$ and Turbak et al. ${ }^{10}$ in the beginning of the 1980s.
The commercialization of MFC has, however, encountered several challenges, two examples of which are the high energy demand and the extensive clogging associated with early production methods. ${ }^{1}$ Therefore, the production of MFC nowadays often involves a pretreatment step prior to the mechanical disintegration of the cellulose fiber as a means of reducing the otherwise highly energy-intensive operation of the high-pressure homogenizer or microfluidizer. ${ }^{11}$ This can be achieved in the form of enzymatical hydrolysis ${ }^{12}$ or various chemical pretreatments, for example, carboxymethylation, ${ }^{13}$ phosphorylation, ${ }^{14}$ and 2,2,6,6-tetramethylpiperidinyl-1-oxyl (TEMPO)-mediated oxidation. ${ }^{15}$ The latter was developed by Saito and Isogai ${ }^{15}$ and is a successful method for facilitating the separation of the fibrils, which is done by introducing repelling forces by converting the primary hydroxyls on the cellulose surface into carboxylate groups.

Another bottleneck in the commercialization of MFC is encountered in the dewatering of the fibrillated suspension. ${ }^{16}$ The cellulose fibrils readily form hydrogen bonds with water,

Received: September 16, 2021

Revised: November 4, 2021

Accepted: November 8, 2021

Published: November 20, 2021

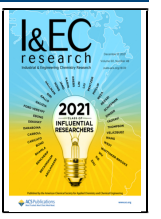


and entanglement of the fibrils causes highly viscous suspensions to be formed. There is a risk of clogging during mechanical disintegration if disintegration is achieved by means of high-pressure homogenizers even at low solid concentrations, and means that dilute process streams are necessary for this process step. A considerable amount of water therefore needs to be removed prior to transportation from the production site (thereby reducing the cost of transportation) and to enable further modification. The removal of water is, however, challenging because of the large surface area of the material and its unique three-dimensional network structure in water that results in a gel-like structure. Methods currently suggested include thermal drying (e.g., spray drying), freeze drying, and super-critical drying, ${ }^{17}$ all of which require an extensive amount of energy as the heat of evaporation of water is high at atmospheric pressure. Moreover, conventional drying techniques may lead to morphological changes (such as particle aggregation), commonly referred to as hornification. ${ }^{18}$ This may result in reduced redispersibility, which, in turn, limits the end use of the material. It is therefore of great interest that as much water as possible is removed prior to the drying step.

A common method employed for reducing the total energy demand is to add a mechanical dewatering step prior to the drying step, with filtration being most commonly used. Unfortunately, this method is not suitable for dewatering MFC suspensions since the large surface area being subjected to the liquid flow along with interfibrillar interactions provides extensive resistance to filtration. A viable option for improving dewatering may be the use of an electroassisted filtration technique that has been used extensively to dewater hard-tofilter materials, such as sludge ${ }^{19-25}$ and clay. ${ }^{26,27}$

Electroassisted filtration of cellulose in the form of microcrystalline cellulose (MCC) has been investigated by Wetterling et al., ${ }^{28,29}$ who showed it to be an efficient method with an energy demand that was not only reasonable but also lower than that of thermal drying. Although MCC and MFC are both cellulosic materials, their inherent characteristics related to particle morphology and flexibility may give rise to different filtration behaviors, for example, in terms of the filter cake structure. $^{30}$ MCC has a cylindrical shape and high crystallinity, which make them rather stiff, whereas MFC has a much larger aspect ratio and contains both crystalline and amorphous regions, which make them flexible. These differences, along with those related to surface charge, confer special properties to the viscosity and stability of the respective suspensions. How these variations, in turn, affect filtration behavior in the presence of an external electric field is not yet fully understood and hence it becomes interesting as well as important to study the electroassisted filtration of MFC. Although Heiskanen et al. ${ }^{31}$ expressed the potential of electroassisted filtration as a means of dewatering MFC in a patent taken out in 2014, no studies on the matter have been published since to the best of the authors' knowledge. Thus, further research is required in the quest to uncover the full potential of electroassisted filtration as a means of dewatering MFC.

Most of the studies regarding the electroassisted filtration of various hard-to-filter materials found in the literature are experimental, often combined with some classical mathematical modeling (e.g., refs 20, 29, and 32). These models describe, for example, how the electric field strength influences the dewatering rate: they do not, however, describe various mechanisms on the micro/nano/ molecular scale, which implies that the underlying dewatering mechanisms have not been completely investigated and understood yet. Classical models are suitable for describing dewatering on the macroscale, but it is important that molecular interactions on the nanoscale are also considered when enhancing the understanding of dewatering. Furthermore, the dewatering mechanism of systems with charged surfaces, e.g., MFC suspensions, becomes even more complex as fibril-fibril and fibril-water interactions at the molecular level play an important role during the removal of water and should be addressed adequately. These types of complex systems exhibit a broad hierarchy of scales, such as the atomic scale, which becomes important at the solid-liquid interface, the electrical double layer (EDL), which can extend to a few nanometers, and the characteristic size of the MFC, which can extend into the micrometer range.

It is therefore very challenging to study the phenomenon on all of the length scales using a unique methodology that describes all of the physics included in the system. A feasible strategy could be to study a microscopic part that represents all of the particle groups, and forces that exist in the system, separately. In this context, molecular dynamics (MD) simulations can act as a "computational microscope" that allows visualization of the molecular motions at high spatial and temporal resolutions. New windows may thereby be opened for developing a deeper understanding of the mechanisms and dynamics of complex systems on the atomic scale where no experimental techniques are currently applicable. Although MD simulations have been used extensively to study the electroosmotic behavior of fluids in nanoconfined spaces, ${ }^{33,34}$ most MD studies have been performed to describe the effect of system properties such as EDL, ${ }^{35,36}$ surface charge, ${ }^{37}$ and ion-specific effects ${ }^{34}$ on electroosmotic flow (EOF) behavior. The authors are unaware of any MD studies that explain the electroassisted dewatering behavior of MFC suspensions that might entail any phenomena related to electric field and pressure, as described above.

The effect of electroassisted filtration of MFC is not fully understood at the present moment. The aims of this study are therefore to study the electroassisted dewatering of MFC produced via TEMPO-mediated oxidation experimentally and further enhance the understanding of the dewatering mechanism at the molecular level through all-atom MD simulations.

\section{THEORY}

Several electrokinetic phenomena occur, including electrophoresis, electroosmosis, ion migration, ohmic heating, and electrolysis, when an electroassisted filtration technique is employed (see Figure 1). While some of these are beneficial to dewatering, others are not. ${ }^{38}$ A detailed review by Mahmoud et al. ${ }^{39}$ provides further details of the different mechanisms involved during an electroassisted dewatering process.

The phenomenon described below applies to a suspension of particles carrying a negative surface charge, as is the case for MFC suspended in an aqueous medium, due to deprotonation of the acidic groups originating from the pulp. ${ }^{40}$ Moreover, the negative surface charges may also stem from chemical pretreatment prior to the mechanical disintegration of the fiber, for example, the introduction of carboxylate groups by TEMPO oxidation. 


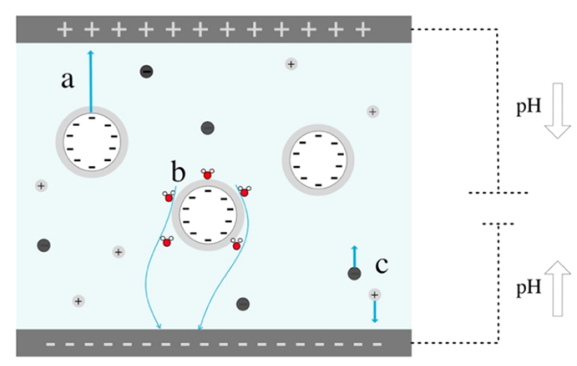

Figure 1. Schematic diagram of the electrokinetic phenomenon that occurs when an electrical field is applied in a suspension with particles carrying a negative surface charge (white circles). Cations: light gray dots; anions: dark gray dots; a: electrophoretic movement; b: electroosmotic dewatering; and c: ion migration.

Electrophoresis, illustrated in Figure 1a, can be beneficial to dewatering if the cathode is placed underneath the filter medium: the relative electrophoretic movement of the negatively charged MFC toward the anode counteracts the buildup of a dense filter cake with high flow resistance. ${ }^{41}$ The disturbed formation of the cake results in its filtration resistance being reduced. However, as the particle movement becomes restricted by, for example, the filter cake, the effect of electrophoresis becomes less pronounced. Furthermore, in the absence of external pressure, the only force counteracting the electrophoretic movement of charged cellulose fibrils toward the anode is the weak gravitational force, which is negligible as compared to electrostatics force exerted by an external electric field onto the fibrils.

Electroosmosis is also considered beneficial under the same conditions as described above. In the solution, a layer of counterions surrounds the negatively charged MFC and forms an electrical double layer, which, upon application of an electric field, is transported toward the cathode along with the bulk water, thereby facilitating dewatering. HelmholtzSmoluchowski's equation (eq 1) is often used to express the electroosmotic flow of water ${ }^{42}$

$$
\frac{v}{E}=\frac{\varepsilon \varepsilon_{0} \zeta}{\eta}
$$

where $v$ is the electroosmotic velocity, $E$ is the strength of the electric field applied, $\varepsilon$ is the relative dielectric constant of the fluid, $\varepsilon_{0}$ is the permittivity of vacuum, $\zeta$ is the $\zeta$ potential, and $\eta$ is the dynamic viscosity of the dispersion medium.

Ohmic heating will occur since there is an electrical resistance and an electric current passing through the system, resulting in an increase in temperature. The temperature increase is proportional to the current and resistance, leading to a reduction of the viscosity and thereby aiding filtration. However, overheating can lead to the destruction of electrodes and the filter medium, for example, and thus have a negative effect. $^{20}$

In addition, ions migrate to the electrode of opposite charge, as shown in Figure 1c. The ions are present in the original suspension and also formed during electrolysis reactions.

Electrolysis reactions take place at the respective electrodes. The extent of the electrolysis reactions is highly influenced by the ionic species present and the materials of the electrodes. ${ }^{39}$ Corrosion is prevented by using "nonconsumable" electrodes made from either mixed-metal titanium meshes, entire graphite plates, or noble metals. ${ }^{43}$ The major reactions that occur are related to water electrolysis ${ }^{44}$

$$
\begin{aligned}
& \text { anode: } 2 \mathrm{H}_{2} \mathrm{O}(\mathrm{l}) \rightarrow 4 \mathrm{H}^{+}+\mathrm{O}_{2}(\mathrm{~g})+4 \mathrm{e}^{-} \\
& \mathrm{M}^{n+}+n \mathrm{e}^{-} \rightarrow \mathrm{M} \\
& \text { cathode: } 2 \mathrm{H}_{2} \mathrm{O}(\mathrm{l})+2 \mathrm{e}^{-} \rightarrow 2 \mathrm{OH}^{-}+\mathrm{H}_{2}(\mathrm{~g}) \\
& \mathrm{M} \rightarrow \mathrm{M}^{n+}+n \mathrm{e}^{-}
\end{aligned}
$$

where $M$ represents the material of the electrode and $\mathrm{M}^{n+}$ represents its cation.

A pH gradient thereby develops between the electrodes due to the formation of hydrogen ions and hydroxide ions when water is being decomposed at the respective electrode. The ionic products may migrate into the filter cake ${ }^{45}$ and can thus alter the properties of the material, such as the surface charge, influencing the efficiency of the dewatering process. The electrolytic reactions also have other consequences, including the formation of a nonconducting gas at the electrodes that causes an electrical resistance to arise. ${ }^{46}$

\section{METHODOLOGY}

The section describes the methodology employed in the experimental and simulation work.

3.1. Experimental Section. 3.1.1. Materials. Dissolving pulp from a Scandinavian pulp mill, $\mathrm{NaClO}(10-15 \%$ available chlorine) from VWR, and TEMPO (98\%) and $\mathrm{NaBr}$ (>99.5\%), both from Sigma-Aldrich, were used for the TEMPO-mediated oxidation experiments (see Section 3.1.2). $\mathrm{NaOH}$ (purity $>98 \%$, Sigma-Aldrich) was used to regulate the $\mathrm{pH}$ during the oxidation process.

3.1.2. TEMPO Oxidation. The method employed is based on Brodin et al. ${ }^{47}$ A $40 \mathrm{~g}$ (dry basis) sample of dissolving pulp from a Scandinavian pulp mill was immersed in deionized water overnight to swell. A homogeneous suspension was then made by first disintegrating the swollen pulp using a standard disintegrator (Noram model G3-13, Lorentzen and Wettre, Canada Inc.) for 60000 revolutions, followed by treatment in a household blender for $5 \mathrm{~min}$. $\mathrm{NaBr}(1 \mathrm{mmol} / \mathrm{g}$ pulp $)$ and catalytic amounts of TEMPO $(0.1 \mathrm{mmol} / \mathrm{g}$ pulp $)$ were dissolved in water and added to the pulp suspension in a baffled vessel under stirring with a four-pitch blade impeller. The reaction was initialized by the dropwise addition of $\mathrm{NaClO}$ carried out at 1 wt $\%$ and at room temperature. Protons are generated during the reaction, so the addition of $0.5 \mathrm{M} \mathrm{NaOH}$ was required to maintain the $\mathrm{pH}$ of $10.1 \pm 0.1$. The reaction was quenched after $70 \mathrm{~min}$ had passed by adding $200 \mathrm{~mL}$ of $99 \% \mathrm{EtOH}$.

The oxidized fibers were separated by vacuum filtration; to retain the smaller fiber fragments, the first volume of the filtrate was recycled. The pulp was then washed thoroughly with deionized water, resulting in the filtrate having a conductivity of $<20 \mu \mathrm{S} / \mathrm{cm}$. The pulp was stored in plastic bags at $4{ }^{\circ} \mathrm{C}$, awaiting further treatment and analysis.

3.1.3. Fibrillated Material. The TEMPO-oxidized pulp was dispersed mechanically to form microfibrillated cellulose, referred to as TEMPO-MFC, using an IKA Ultra-Turrax T50 with a dispersing element (S50 N-G45F) and a dispersing unit operating via the rotor/stator principle. ${ }^{48}$ Dispersion was performed at $10000 \mathrm{rpm}$ for a $4 \mathrm{~min} / \mathrm{g}$ TEMPO-oxidized pulp. The temperature increased during the mechanical treatment, so the suspension was kept in an ice bath to limit evaporation losses. The mechanical treatment took place at $1 \mathrm{wt} \%$ to prevent the suspension from becoming too viscous. The dry 
content was determined using a Sartorius Moisture Analyser performed in a minimum of duplicates.

3.1.4. Characterization. The raw materials, the TEMPOoxidized pulp and TEMPO-MFC, were analyzed as described below.

3.1.4.1. Compositional Analysis of the Dissolving Pulp. The composition of the pulp was determined using a method devised by Theander and Westerlund, ${ }^{49}$ whereby acid hydrolysis, using sulfuric acid, is followed by quantification of the monomers using high-performance anion-exchange chromatography with pulsed amperometric detection (HPAEC-PAD). Lignin was quantified as being either acidsoluble lignin (ASL) and Klason lignin (KL). The amount of ASL was calculated from its absorbance, as measured with UV at $205 \mathrm{~nm}$ (Specord 205, Analytik Jena) using an absorptivity constant of $110 \mathrm{dm}^{3} /(\mathrm{g} \mathrm{cm})$, whereas the amount of $\mathrm{KL}$ was determined gravimetrically. Further details can be found in Wojtasz-Mucha et al. ${ }^{50}$

3.1.4.2. Attenuated Total Reflectance Fourier Transform Infrared Spectroscopy (ATR-FTIR). Both the dissolving pulp (unoxidized) and the TEMPO-oxidized pulp were dried at 60 ${ }^{\circ} \mathrm{C}$ for at least $24 \mathrm{~h}$ prior to analysis to remove any residual moisture. The pulp sample was placed on top of an attenuated total reflectance (ATR) crystal and secured with a clamp to ensure even pressure. A PerkinElmer Frontier, equipped with an ATR, was used to record the infrared spectrum in transmittance mode with a resolution of $4 \mathrm{~cm}^{-1}$ from a wavenumber of $400-5000 \mathrm{~cm}^{-1}$, once a sample of background of air had been collected.

3.1.4.3. $\zeta$ Potential. A Zetasizer Nano ZS (Malvern Instruments) was used to measure the $\zeta$ potential of the TEMPO-MFC. Prior to the measurement, the TEMPO-MFC was diluted to $0.05 \mathrm{wt} \%$ and the ionic strength was adjusted to $5 \mathrm{mM}$ using $\mathrm{NaCl}$. The measurements were performed in triplicate at $25{ }^{\circ} \mathrm{C}$ in capillary-folded cuvettes.

3.1.4.4. Carboxylate Content. A method described by Mautner et al., ${ }^{51}$ based on the work of Saito and Isogai, ${ }^{52}$ was employed to determine the carboxylate content of the TEMPO-MFC. In brief, $0.15 \mathrm{~g}$ (dry basis) TEMPO-MFC was diluted to $60 \mathrm{~mL}$ using deionized water, before the conductivity was adjusted by adding $5 \mathrm{~mL}$ of $0.01 \mathrm{M} \mathrm{NaCl}$. Protonation of the sample was achieved by the dropwise addition of $0.1 \mathrm{M} \mathrm{HCl}$ until a $\mathrm{pH}$ of $2.5-3$ was reached. The suspension was allowed to stabilize before titration with 0.04 $\mathrm{M} \mathrm{NaOH}$ using an automatic titrator (TitroLine 7000, SI analytics) with a dosing rate of $0.1 \mathrm{~mL} / \mathrm{min}$. The conductivity was monitored using a digital conductivity meter (model CO $301, \mathrm{VWR}$ ), and the titration was aborted at a $\mathrm{pH}$ of $11 . \mathrm{N}_{2}$ was purged through the suspension for the duration of the titration to limit the influence of $\mathrm{CO}_{2}$. The carboxylate content was calculated according to eq 2 ; thus

$$
n=\frac{\left(v_{1}-v_{0}\right) c_{\mathrm{NaOH}}}{m}
$$

where $n$ is the carboxylate content (mmol/g TEMPO-MFC), $v_{1}$ and $v_{0}$ are the volumes of $\mathrm{NaOH}(\mathrm{mL})$ at the intersection points between the plateau and the linear regions and are determined graphically, $c_{\mathrm{NaOH}}$ is the concentration of $\mathrm{NaOH}$ $(\mathrm{mmol} / \mathrm{mL})$, and $m$ is the mass of TEMPO-MFC $(\mathrm{g})$. The titrations were performed in duplicate.

The carboxylate content of the dissolving pulp was determined according to the protocol described by SCAN-
CM 65:02 using eq 2, in which $m$ is changed to equal the mass of the pulp and thereby makes $n$ equal to $\mathrm{mmol} / \mathrm{g}$ pulp.

3.1.4.5. Brunauer-Emmett-Teller (BET) Surface Area. The specific surface area was determined using nitrogen adsorption at $77 \mathrm{~K}$ using an 8-point BET method (Micromeritics TriStar 3000). Irreversible collapse of the pores of the TEMPO-MFC upon drying was prevented by employing a solvent exchange procedure. ${ }^{53}$ The suspension was dewatered carefully before being subjected to displacement washing and, finally, shaken in acetone five times. The procedure was repeated with cyclohexane, whereafter the sample was dried in a nitrogen atmosphere for $8 \mathrm{~h}$. The sample was degassed at 75 ${ }^{\circ} \mathrm{C}$ for $18 \mathrm{~h}$ prior to analysis.

3.1.4.6. Morphology. The morphology of the TEMPOMFC was analyzed by scanning electron microscopy (SEM) using an FEI Quanta200 ESEM operating at an acceleration voltage of $3 \mathrm{kV}$. Prior to analysis, a droplet of $0.005 \mathrm{wt} \%$ TEMPO-MFC was placed on top of a polished SEM stub and allowed to air-dry overnight, whereafter the sample was sputtered with palladium for $60 \mathrm{~s}$.

3.1.5. Filtration Equipment. A pneumatically driven, benchscale, filtration setup (see Johansson et al. ${ }^{54}$ for details) was modified so that electroassisted filtration could take place (Figure 2). ${ }^{29}$

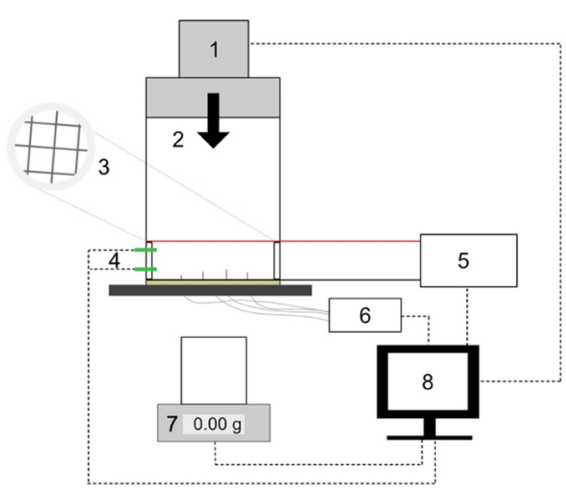

Figure 2. Schematic diagram of the filtration unit. 1: Piston press with its position recorded. 2: Plexiglass filter cell, with four pressure capillaries located at different heights. 3: Close-up of the anode (a mesh of platinum wires with square openings). 4: Thermocouples. 5: Power supply (current, voltage, and power recorded). 6: Pressure transducers. 7: Balance. 8: Data acquisition unit.

The filter cell has an inner diameter of $60 \mathrm{~mm}$ and a total height of $175 \mathrm{~mm}$; the lower part, made of plexiglass $(h=115$ $\mathrm{mm}$ ), is placed upon a perforated bottom plate of plastic. A supporting rack with a height of $30 \mathrm{~mm}$ is placed at the lowest part of the filter cell, thereby reducing the internal diameter to $50 \mathrm{~mm}$. The pressure capillaries, which are made of perfluoroalkoxy alkene (PFA), are mounted through the bottom plate and have circular holes, $0.6 \mathrm{~mm}$ in diameter, located perpendicular to the flow at a distance from the filter medium of $2,4,6$, and $8 \mathrm{~mm}$, respectively. The pressure capillaries are connected to pressure transducers (Kristal Instrument $\mathrm{AG}$, an accuracy of $10 \mathrm{kPa}$ ). The mass of the filtrate is logged using a balance (Mettler Toledo SB 32000) with an accuracy of $0.5 \mathrm{~g}$.

Two electrodes, separated at a constant distance of $25 \mathrm{~mm}$, are connected to a DC power supply (EA-PSI 5299-02 A, Elektro-Automatik). The bottom electrode is a platinum mesh (Unimesh 300) placed on the bottom plate, beneath the 
support filter and the filter medium; the upper electrode is a mesh of platinum wire of diameter $0.25 \mathrm{~mm}$ placed on the supporting rack inside the filter cell.

LabVIEW (software version 15.0, National Instruments) logs the absolute hydrostatic pressure, the position of the piston, the mass of the filtrate, current, power, voltage, and temperature. The temperature in the filter cell is measured by two PFA-coated K-type thermocouples placed at distances of 5 and $20 \mathrm{~mm}$, respectively, from the filter medium.

3.1.6. Experimental Conditions. The day prior to the experiment, a 1 wt \% slurry was prepared from the TEMPOoxidized pulp (see Section 3.1.3). An approximate mass of 500 $\mathrm{g}$ was used for each experiment.

All experiments were performed at room temperature using a hydrophilic poly(ether sulfonate) (PES) membrane (Supor 100 , PALL corporation) as the filter medium. According to the manufacturer, this membrane has a nominal pore size of 0.1 $\mu \mathrm{m}$ and a typical water flow rate at 0.7 bar of $5 \mathrm{~mL} /\left(\mathrm{min} \mathrm{cm}^{2}\right)$. In addition, Munktell filter grade 5 was used as a support.

The electroassisted filtration experiments were run at a constant applied pressure of 3 bar. The electric field strength was examined at four levels: $0,6,12$, and $24 \mathrm{~V} / \mathrm{cm}$, referred to as $\mathrm{P}, \mathrm{L}, \mathrm{M}$, and $\mathrm{H}$, respectively. Supplementary experiments, referred to as E, were also performed: these had an electric field of $24 \mathrm{~V} / \mathrm{cm}$, and no pressure was applied. All experiments with electric fields were run in constant voltage mode.

3.2. Computational Method. All of the MD simulations were performed using GROMACS2019 software, which has been used extensively to study the atomistic details of systems involving biomolecules ${ }^{55,56}$ and polymers; ${ }^{55,57}$ a time step of 2 fs and a cutoff distance of $1.1 \mathrm{~nm}$ for truncating the van der Waals force were applied. Long-range electrostatic interactions were calculated using the smooth particle mesh (SPME) method. ${ }^{58}$ All of the simulations were performed in canonical ensemble (NVT) at $298 \mathrm{~K}$. Systems involving electric fields may exhibit statistically different temperatures and give rise to athermal effects, ${ }^{59}$ so the temperature was controlled by a velocity rescaling thermostat (V-rescaling): this is a modified version of the Berendsen thermostat, which has been shown to enforce the correct canonical ensemble. ${ }^{60,61}$ Periodic boundary conditions were applied in every direction throughout the simulations. Water molecules were described using the SPC/E model $^{62}$ due to its close agreement with experimental hydrogen bond dynamics ${ }^{63}$ and surface tension. ${ }^{64}$ The bonds and angles of the water molecules were conserved using the SETTLE algorithm.

The TEMPO-oxidized cellulose (TOC) was constructed based on an atomistic model ${ }^{65}$ of a cellulose chain composed of 12 glucose molecules. Every second hydroxymethyl group was substituted with a carboxylate group to represent the TOC chain. ${ }^{66}$ A TOC slab was modeled as a slab of nanocrystalline cellulose $(\mathrm{CNC})^{67}$ where every alternate hydroxymethyl group on the CNC chain on one of the free surfaces was substituted by a carboxylate group, as shown in Figure 3.

Although there are several force fields (FFs), such as AMBER, ${ }^{68} \mathrm{CHARMM}^{69}$ and GROMOS, ${ }^{70}$ that can be used to describe carbohydrate molecules, GLYCAM06 ${ }^{71}$ FF was implemented in this study to describe the cellulose chains. It has been employed in various condensed phase simulations of biomolecules ${ }^{72-74}$ and has been proved to predict the surface and mechanical characteristics of nanocrystalline cellulose and its interaction with aqueous media. ${ }^{67,75}$ The interaction

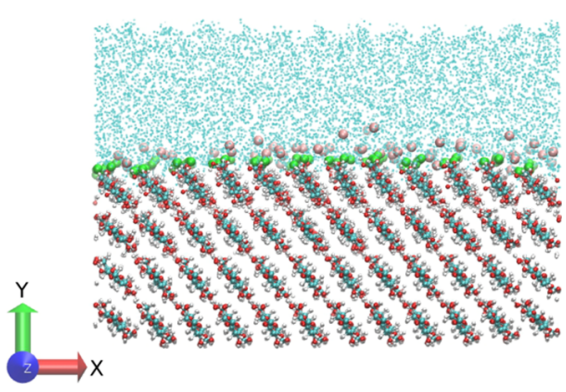

Figure 3. Schematic image of a slab of surface-modified TOC fibril. Blue dots: water molecules. Pink dots: sodium ions. Green spheres: oxygen atoms of carboxylate groups on the TOC surface.

parameters between water and cellulose chains were described using Lorentz-Berthelot mixing rules.

\section{RESULTS AND DISCUSSION}

4.1. Characterization of the Dissolving Pulp. Prior to oxidation, the dissolving pulp had a carboxylate content of $0.025 \pm 0.002 \mathrm{mmol} / \mathrm{g}$ pulp, with the majority being composed of glucose followed by minor amounts of xylose and mannose: a typical composition of the dissolving pulp. The percentage (including standard deviation) of the respective constituents is reported in Table 1.

4.2. Characterization of TEMPO-MFC. The overlapping ATR-FTIR spectra of the unoxidized and TEMPO-oxidized pulps in Figure 4 show a noticeable difference at a wavenumber of around $1603 \mathrm{~cm}^{-1}$, marked with a red dashed line. This has been reported to correspond to the stretching of $\mathrm{COO}^{-}$in the sodium form, thereby conforming to the successful TEMPO oxidation. $^{76}$ The remaining peaks can be found in the Supporting Information.

Conductometric titration confirmed a carboxylate content of $1.08 \pm 0.02 \mathrm{mmol} / \mathrm{g}$ TEMPO-MFC. The presence of the carboxylate groups on the fibrils makes them negatively charged, thereby resulting in a $\zeta$ potential of $-42.3 \pm 1.5 \mathrm{mV}$.

The TEMPO-MFC had a large specific surface area of $218 \pm$ $12 \mathrm{~m}^{2} / \mathrm{g}$, obtained using the BET method after undergoing the solvent exchange described. A wide range of surface areas have been reported for microfibrillated cellulose in the literature: $199-420 \mathrm{~m}^{2} / \mathrm{g}^{77}$ and $41.8-375 \mathrm{~m}^{2} / \mathrm{g}^{78}$ The wide span is due to inherent differences between the fibrillated materials related to the raw material and the production method, along with the different analytical techniques employed for determining the surface area. It is therefore difficult to make comparisons with the values presented, although they are all on the same order of magnitude. Table 2 shows a summary of the characteristics of the TEMPO-MFC, including $\zeta$ potential, carboxylate content, and BET surface area.

The SEM micrographs in Figure 5 show a network of fibrils with a wide size distribution. Some fiber structures remain even after oxidation and disintegration. The larger structures observed in Figure 5a may also have been formed due to the aggregation of fibrils upon drying. Smaller fibrils can be detected, too: Figure $5 \mathrm{~b}$ shows a cellulose fibril with a length of approx. $14 \mu \mathrm{m}$.

4.3. Experimental Results: Electroassisted Filtration. Figure 6 shows the dewatering rate vs time for the different cases: with only applied pressure $(P)$, only applied electric field $(E)$, and with a combination of the two with varying electric field strengths $(L, M$, and $H)$. It is evident that the dewatering 
Table 1. Composition of the Dissolving Pulp Expressed as \%, Including Standard Deviations $n=5$

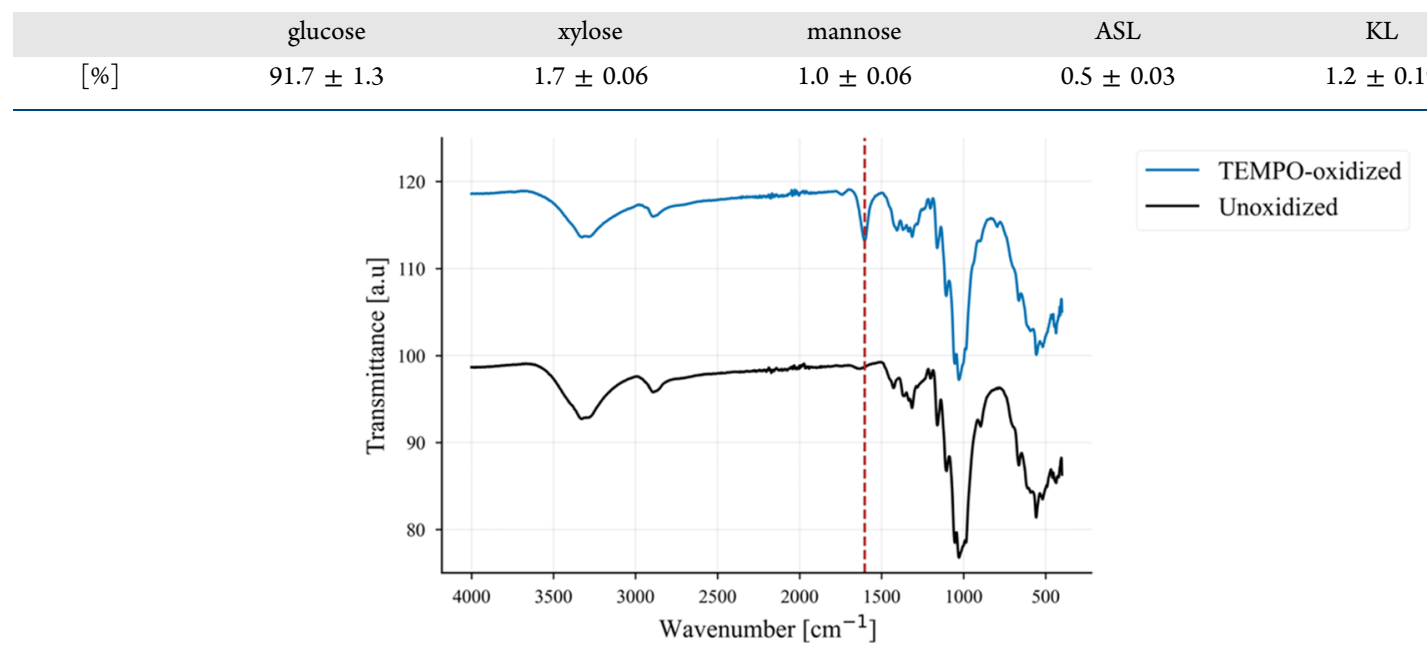

Figure 4. ATR-FTIR spectra of the unoxidized (black) and TEMPO-oxidized (blue) pulps. The red dashed line at $1603 \mathrm{~cm}^{-1}$ marks the stretching of $\mathrm{COO}^{-}$.

Table 2. Summary of the Characteristics of the TEMPOMFC

\begin{tabular}{ccc}
$\begin{array}{c}\zeta \text { potential } \\
(\mathrm{mV})\end{array}$ & $\begin{array}{c}\text { carboxylate content }(\mathrm{mmol} / \mathrm{g} \\
\text { TEMPO-MFC })\end{array}$ & $\begin{array}{c}\text { BET surface area } \\
\left(\mathrm{m}^{2} / \mathrm{g}\right)\end{array}$ \\
$-42.3 \pm 1.5$ & $1.08 \pm 0.02$ & $218 \pm 12$ \\
\hline
\end{tabular}

rate is very low when just pressure is applied and improves slightly when only an electric field is applied, as can be seen by comparing the yellow squares $(P)$ with the blue triangles $(E)$. However, when mechanical pressure and electric field are combined, the dewatering rate increases substantially $(H, M$, and $L$ ).

Clearly, mechanical pressure alone is insufficient to promote dewatering of the TEMPO-MFC suspension. When the filtration cell was dismantled after $24 \mathrm{~h}$ of filtration, it was observed that a thin and compact filter cake had been formed: this may be due to the initial layer of particles deposited on the membrane being densely compacted. In combination with the large surface area of TEMPO-MFC subjected to the liquid flow, it can lead to an extensive filtration resistance and, as a consequence, virtually nonexistent dewatering after less than $30 \mathrm{~min}$. Amini et al. ${ }^{79}$ also found that the dewatering rate decreased early on when they evaluated the pressure filtration of cellulose nanofibrils. It is not only the presence of a highly compact initial layer that can contribute to the extensive filtration resistance: it is also important that the mechanical interlocking between the fibrils and/or friction between the fibrils is taken into consideration.

When only an electric field was applied, the dewatering rate was observed to be improved at first compared to solely applying pressure, but dewatering ceased after less than 20 min. A rapid decline in current density was seen (Figure 8), indicating the development of extensive electrical resistance within the system. The reason behind this high resistance is not fully understood and will be the topic of our upcoming studies.

Moreover, the dewatering rate increased considerably when the mechanical pressure and electric field were combined (cf. $L, M$, and $H$ in Figure 6). The figure also displays the effect of increasing the strength of the electric field: an increase in the
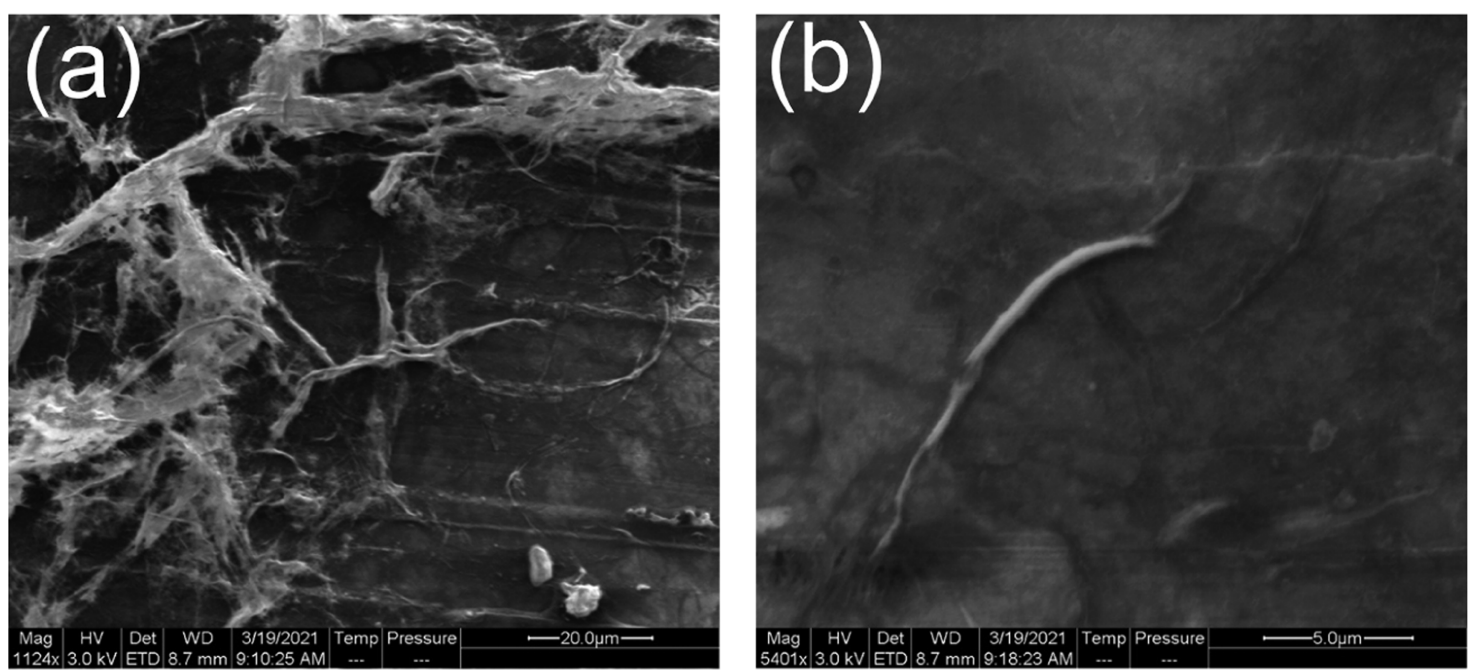

Figure 5. SEM micrograph of TEMPO-MFC at magnifications of (a) $1124 \times$ and (b) 5401×. 


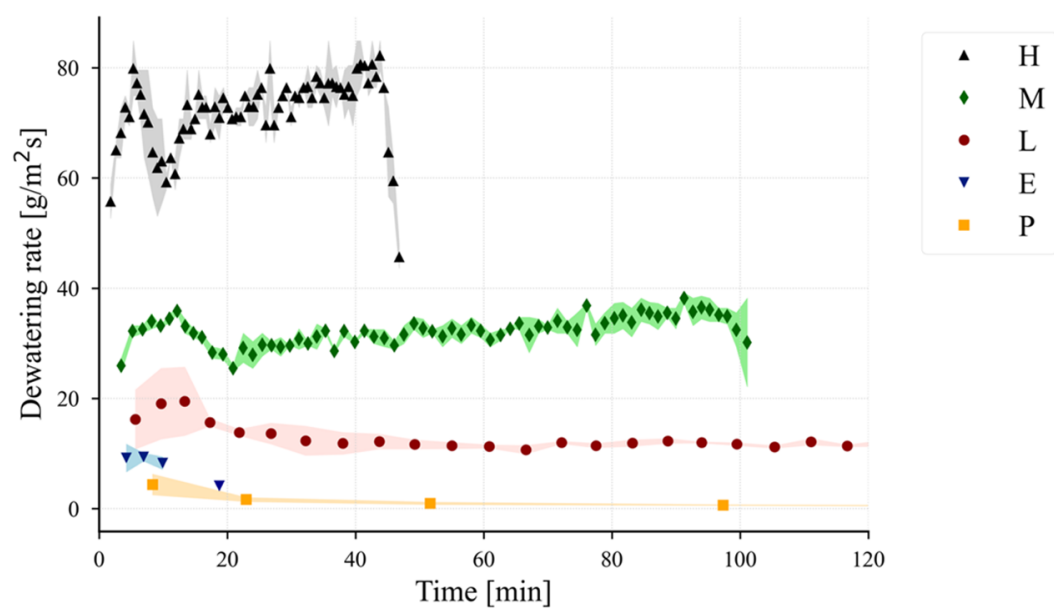

Figure 6. Dewatering rate vs time, including standard deviation (shaded area) obtained from duplicate measurements. $H=24 \mathrm{~V} / \mathrm{cm}, M=12 \mathrm{~V} /$ $\mathrm{cm}, L=6 \mathrm{~V} / \mathrm{cm}$, and $P=0 \mathrm{~V} / \mathrm{cm}$, all with an applied pressure of $3 \mathrm{bar} . E=24 \mathrm{~V} / \mathrm{cm}$, but with no applied pressure.

applied voltage generates an increase in the dewatering rate, as reported previously, e.g., by Olivier et al. ${ }^{80}$ and Gözke et al. ${ }^{81}$ The dewatering rate is proportional to the strength of the electric field, which can be expected from HelmholtzSmoluchowski's equation (eq 1 ).

The increase in dewatering is not caused solely by the electrokinetic phenomenon that occurs when a combination of an electric field and mechanical pressure is used. A noteworthy observation was made when studying the dewatered structure presented in Figure 7: the formation of channels. This type of structure enables high overall permeability and an enhanced flow of water upon the application of mechanical pressure. The meshed design of the anode gives rise to sections with a localized electric field. Previous studies have shown that TEMPO-oxidized cellulose fibrils tend to align themselves parallel to an external electric field, ${ }^{82-84}$ so the TEMPO-MFC may align in the direction of the localized electric field between the electrodes in the filter cell. In addition, the electrophoretic movement of the TEMPO-MFC causes aggregation onto the platinum wires of the anodic mesh. The flow of water takes place through the square openings of the mesh, an example of which is indicated by the red arrow in Figure 7b. TEMPOMFC that enters the lower part of the filter cell is dragged along with the water and thereby the channeled structure is stabilized, as these cellulose particles are stacked onto the existing fibril clusters due to the electrophoretic movement toward the anode and potential alignment in the electric field. A schematic diagram of the suggested development of the structure is shown in Figure $7 \mathrm{c}$.

The density of the current increased during the course of the electroassisted filtration, as can be seen in Figure 8. A higher concentration of TEMPO-MFC, in combination with an increased concentration of ionic species from the electrolysis reaction, contributes to the increasing trend. The increase in current density was only slight for the two lower voltages, while it was more pronounced for the higher voltages. It should be noted that the current density is expected to be higher locally, in the immediate vicinity of the platinum wires of the anode, because of the design of the electrode. Although the formation of char has been observed at the anode at high current densities in previous studies, ${ }^{85}$ no such observation was made in the present study.

The passage of a current through the system causes ohmic heating, which, in turn, leads to an increase in temperature (a)

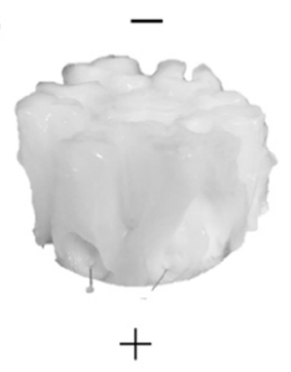

(c)

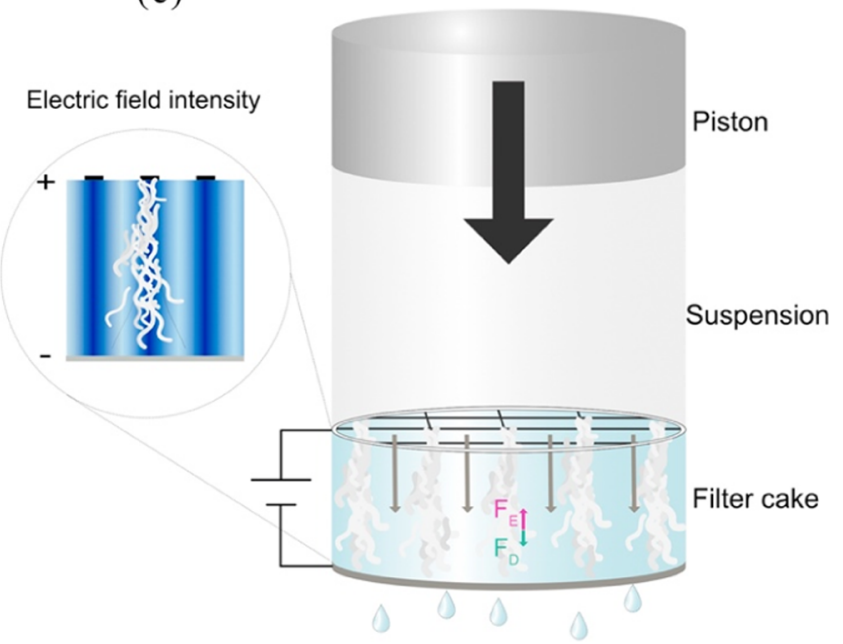

Figure 7. (a) Photograph, showing a frontal view of the formed structure $(12 \mathrm{~V} / \mathrm{cm}$ and $3 \mathrm{bar})$, with the locations of the electrodes $(+$, anode and - , cathode). (b) Overhead view, as seen from the cathode. Red arrow: example of a flow channel. (c) Schematic diagram of the suggested development of the channeled structures. Gray arrows: liquid flow through some of the square openings. Pink arrow $\left(F_{\mathrm{E}}\right)$ : electrophoretic force. Turquoise arrow $\left(F_{\mathrm{D}}\right)$ : drag force on the TEMPO-MFC. Inset: close-up of the lower part of the filter cell, seen from the front. The gradient shows the electric field: the darker the color, the higher its intensity.

(27-32 ${ }^{\circ} \mathrm{C}$ for $L, M, H$ ) (see Figure S1). This ohmic heating is related to the current density, i.e., it is expected that the 


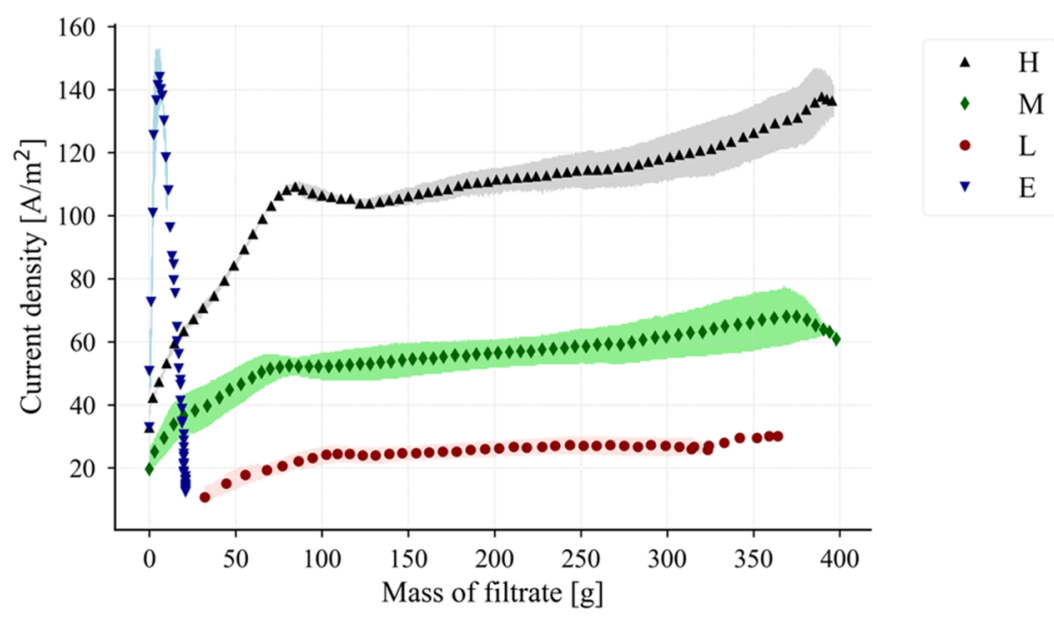

Figure 8. Current density vs mass of filtrate, including standard deviation (shaded area) obtained from duplicate measurements. $H=24 \mathrm{~V} / \mathrm{cm}, M=$ $12 \mathrm{~V} / \mathrm{cm}, L=6 \mathrm{~V} / \mathrm{cm}$, all with an applied pressure of $3 \mathrm{bar} . E=24 \mathrm{~V} / \mathrm{cm}$, but with no applied pressure.

increase in temperature will increase with increasing current density. An increase in temperature reduces the viscosity of the liquid in the suspension and thereby aids dewatering. ${ }^{38}$

4.4. Simulation Results: Electroassisted Filtration. The simulation systems used in this study employ TOC slabs, sodium ions, and water molecules. The main interest here is the behavior of TOC, ions, and water molecules under the influence of the external electric field and pressure to understand the dewatering phenomenon. In this study, different simulation systems are studied, as described in the respective sections, to observe the aforementioned effects.

It is generally accepted that the water molecules confined in complex colloidal systems such as MFC suspensions can be categorized into four different groups: (a) free water or bulk water that is not attached to the particles or influenced by surface forces, (b) interstitial water that is trapped between the cellulose fibrils, (c) surface water that is held on the surface of the cellulose surfaces by adsorption and adhesion, and (d) intercellular and chemically bound water. The latter is, however, of no interest in this simulation study because it is impossible to remove these water molecules using filtration techniques.

4.4.1. Influence of Electric Field and Pressure on the Fibril Movement. The simulation setup for investigating the influence of electric field and pressure forces on the movement of the TOC fibrils was constructed as follows: two surfacemodified TOC slabs $6.38 \times 2.52 \times 6.22 \mathrm{~nm}^{3}$ in size were placed in a periodic simulation domain of $15 \times 12.6 \times 6.22$ $\mathrm{nm}^{3}$. The TOC fibrils were aligned in parallel with the 110 crystal plane, facing each other, as shown in Figure 9. The simulation box was then filled with 35625 molecules of water, and the surplus charge in the domain created due to the carboxylate groups was neutralized by adding an adequate number of sodium ions. The system was energy-minimized and equilibrated in an NVT ensemble at $298 \mathrm{~K}$ for $2 \mathrm{~ns}$. The temperature of the systems was maintained constant throughout the simulation by a V-rescaling thermostat with a time constant of $1 \mathrm{ps}$. An acceleration of $0.00112 \mathrm{~nm} / \mathrm{ps}^{2}$ was subsequently applied to all carbon atoms of the fibrils on the top TOC fibril to generate a simulated pressure acting on it in a positive $Y$-axis, such that the ratio of force exerted by the highest magnitude of the applied electric field $\left(F_{\mathrm{e}}\right)$ to the force exerted by pressure effect $\left(F_{\mathrm{p}}\right)$ was 250 . This ratio was maintained constant throughout the study and is lower than

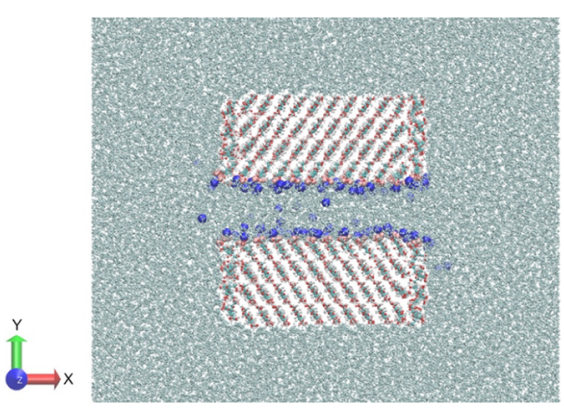

Figure 9. Schematic diagram of the setup used to study the influence of an external electric field and pressure on the movement of fibrils. Purple dots: sodium ions. Pink dots: carboxylate group on the TOC surface. Blue dots: water molecules.

those calculated for the experiments. The bottom fibril was maintained fixed by imposing position restraints in the $X$ - and $Y$-axes. Similarly, the oxygen molecules in the water were also subjected to an acceleration of $0.00018 \mathrm{~nm} / \mathrm{ps}^{2}$ to generate a similar force per unit area as that of cellulose fibril in the positive direction of the $Y$-axis. This acceleration field technically simulates a flow under a pressure difference of 20 bar (20B). An electric field was applied in the perpendicular direction (+ve $Y$-axis) to the TOC fibrils. The trajectory of the center of mass (COM) was then calculated at different field strengths (see Figure 10).

The COM movement of the mobile fibril relative to the fibril at rest is influenced directly by the strength of the external electric field applied, as shown in Figure 10. While the average velocity of the TOC fibril increases with the increasing electric field, the difference in velocities between the cases where the combined electric field and pressure is applied compared to those where only an electric field is applied remains approximately constant. It is worth noting that the velocity ratio of the TOC slabs in the case with only pressure applied to that where the combined pressure and an electric field of $1 \mathrm{~V} /$ $\mathrm{nm}$ are applied is approximately 10 -fold. Therefore, it can safely be stated that the applied pressure has a negligible effect on the COM movement, suggesting that the main driving force of the electrophoretic movement of the negatively charged TOC toward the anode is the applied electric field.

Figure 10 also suggests that the intermolecular repulsive forces between the fibrils become significant at the distance 


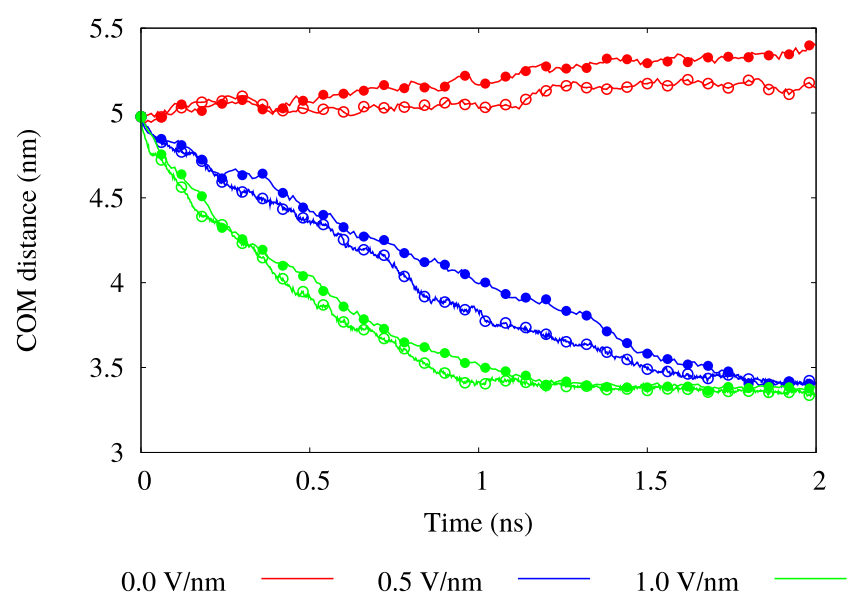

Figure 10. Simulated movement of the COM of a TOC fibril relative to a fixed TOC fibril. Open circles: only the electric field applied. Filled circles: both the electric field and pressure effect (20B) applied. The lower TOC is fixed in all directions using position restraints, while the upper TOC is free to move under the influence of the applied forces.

below $1 \mathrm{~nm}$ from the TOC surface, ${ }^{66}$ as indicated by the nonlinear acceleration in the opposite direction to the fibril movement, which eventually vanishes.

4.4.2. Velocity Profile of Water between the TOC Fibrils. The negatively charged TOC experiences electrophoretic movement toward the anode during the dewatering process. Moreover, the negative surface charge on TOC gives rise to a well-defined electrical double layer with a net charge. A general picture of EDL suggests an immobile layer of counterions near the solid surface and a diffuse mobile layer of counter and coions away from the charged surface. ${ }^{86}$ In addition, the water molecules experience a hydrodynamic drag force toward the cathode due to the overall movement of cations toward it, which causes the movement of water molecules that are "trapped" between the TOCs. Having already observed that the applied pressure makes a negligible contribution to the movement of fibrils, it became of interest to investigate the movement of water molecules between the fibrils under the influence of pressure and an external electric field. For this, a $2.1 \mathrm{~nm}$ wide channel was constructed in a simulation domain of $6.38 \times 10.8 \times 6.22 \mathrm{~nm}^{3}$, as depicted in Figure 11. The channel was filled with 2754 water molecules, and the system

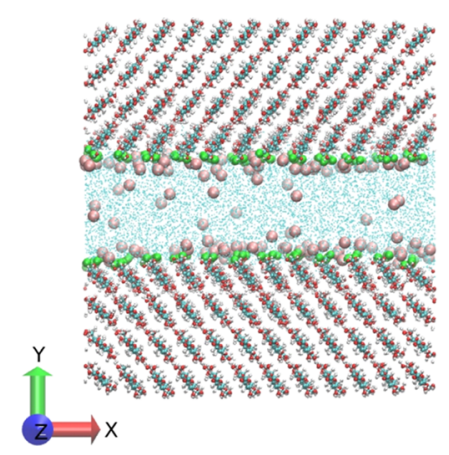

Figure 11. Schematic diagram of the setup used to study the electroosmotic flow. Pink spheres: $\mathrm{Na}^{+}$ions. Green spheres: carboxylate group on the TOC surface. Both the acceleration field to simulate the pressure and the electric field are applied to the positive $X$-axis. was neutralized with $120 \mathrm{Na}^{+}$ions. Periodic boundary conditions were applied in all directions, and the temperature of the system was maintained at $298 \mathrm{~K}$. The system was then equilibrated at NVT for $2 \mathrm{~ns}$, and the system was relaxed for 1 ns at the NVE ensemble. Subsequently, an external acceleration was applied to each oxygen atom of the water molecules in the direction parallel to the wall-water interface in the $X$-axis for $50 \mathrm{~ns}$ to simulate the flow of water. The magnitude of $F_{\mathrm{e}} / F_{\mathrm{p}}$ at an applied field of $1 \mathrm{~V} / \mathrm{nm}$ was maintained to be 250 . The first $20 \mathrm{~ns}$ were excluded from the analysis; the velocity profile of the water molecules along the channel width was extracted from the last $30 \mathrm{~ns}$.

The velocity profile of the water molecules in the channel is shown in Figure 12, where the external electric field is $0.5 \mathrm{~V} /$

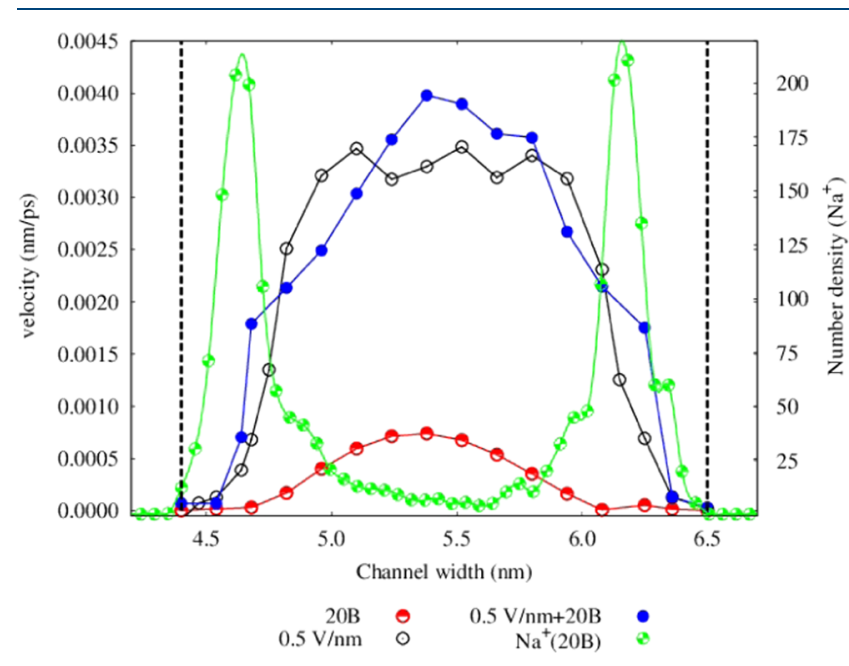

Figure 12. Velocity profiles of water molecules within a $2.1 \mathrm{~nm}$ wide TOC channel. B: pressure effect (semifilled red circles). Black open circles: pure EOF velocity profile. Blue-filled circles: both electric field and the pressure effect applied. Dotted black lines: location of the TOC channel walls. Green lines: number density of sodium ions across the channel with no applied electric field.

$\mathrm{nm}$; the case with an applied electric field of $1 \mathrm{~V} / \mathrm{nm}$ can be found in the Supporting Information (Figure S2). The velocity profiles in Figure 12 indicate that there are layers of $\mathrm{Na}^{+}$ions adjacent to the walls. The velocity profile of the water molecules with only an acceleration field to simulate pressure effect (20B) and no electric field applied shows a general parabolic profile characteristic of Poiseuille's flow, with a negative slip length of approximately $0.8 \mathrm{~nm}$. This indicates that the hydrated $\mathrm{Na}^{+}$ions are strongly attached to the negatively charged TOC walls and resist any movement, which is in line with Stern's theory of EDL, where a molecular layer of counterions adjacent to a charged surface remains immobile and resists any movement and the flow is primarily due to the movement of water molecules and ions in the bulk and diffuse part of EDL. Similarly, when only an electric field is applied to the system, shown by black open circles in Figure 12, the ions adjacent to the walls start moving and drag water molecules along them. The center of the channel shows a plug-flow profile, however, characteristic of the electroosmotic flow (EOF) of water molecules.

The results indicate that the velocity profile of the water molecules under the combined effect of an electric field and pressure effect, simulated by the acceleration field, has characteristics from both a pure Poiseuille's flow and EOF. 


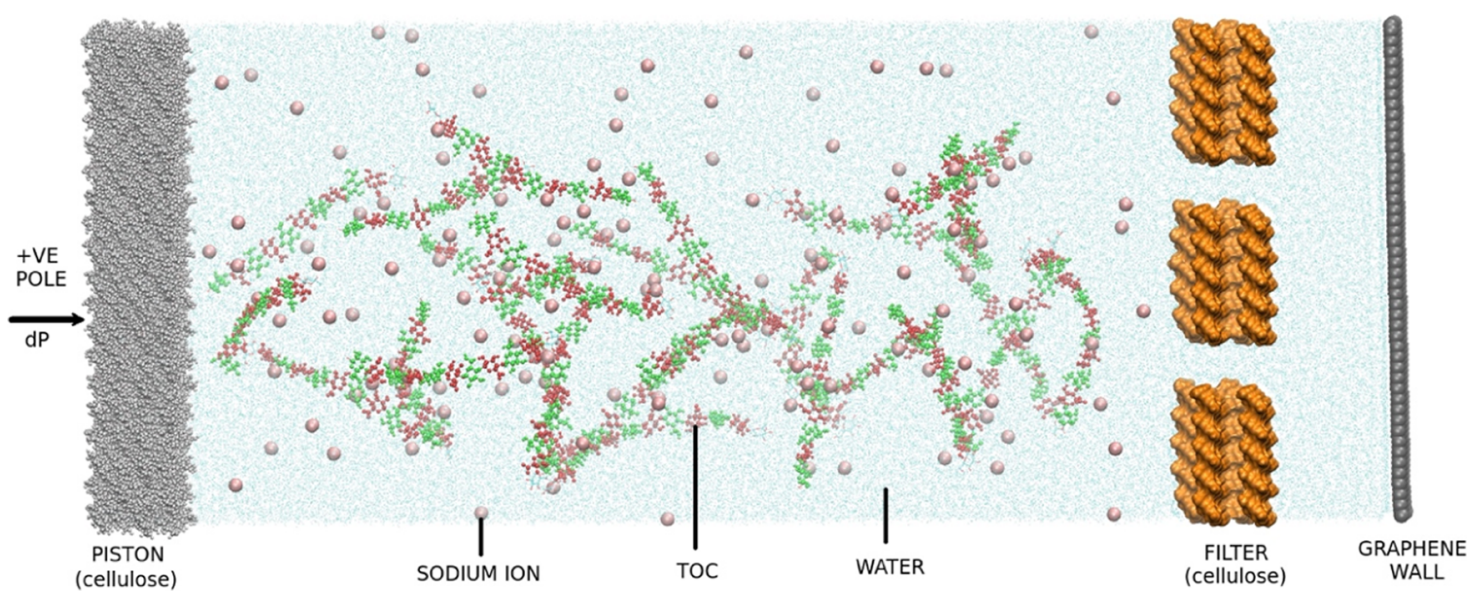

Figure 13. Schematic diagram of the setup used for the electroassisted dead-end filtration. Pink spheres: sodium ions. Piston and filter medium: uncharged cellulose walls.

The center of the channel shows a parabolic profile, while it appears that the adsorbed ions near the TOF walls exhibit a velocity higher than the other cases discussed in this section. Moreover, there still seem to be some ions strongly adsorbed to the TOC walls (Stern layer) that resist any movement. It nevertheless seems that the flow of water molecules in the TOC channel increases, to some extent, when both pressure and an external electric field are applied. When compared to the case with pure EOF, there is only a $14 \%$ increase in the maximum velocity at the center of the channel when both pressure and electric field are applied, while an increase of approximately $360 \%$ is observed in the case where only acceleration field is applied.

Figure 12 indicates that, for the conditions investigated, an externally applied electric field is the main driving force of the flow of water molecules observed in the TOC channel, while pressure has a negligible effect on the velocity of the flow. The water molecules adsorbed to the TOC surfaces and the sodium ions are affected mildly by external forces, such as electric field and pressure, and hence contribute less to the fluid flow between the fibrils. Nevertheless, interstitial water, i.e., the water trapped between the fibrils, is affected by both the electric field and the pressure effect and thus contributes to the water flow: this influences the amount of free water present in the system.

4.4.3. Electroassisted Filtration of TOC Suspension. Having studied the movement of fibrils and the water molecules between them in the presence of electric field and pressure, the overall effect these factors have on the electroassisted filtration of TOC fibrils becomes of interest. Although it is impossible to simulate the entire experimental system in MD simulations due to the time and length scales associated with this technique, as mentioned previously, it was decided that a microscopic part of the system with TOC oligomers of 11 glucose molecules oxidized in the alternate hydroxymethyl group be considered. It should be noted that an exact representation of the experimental dead-end filtration setup is not claimed here: it is, instead, a general setup to explore the physical effects that an electric field and an external pressure have on the system. For instance, complex electrolysis phenomena and the resultant $\mathrm{pH}$ gradient created between the electrodes, which might have a significant effect on the aggregation and dewatering processes, have not been taken into account, along with the mechanical interlockings and friction between the fibrils.

The filtration system is illustrated in Figure 13. The graphene wall is placed at the filter end of the system to prevent the escape of water molecules and also to apply a negative pressure to the system to guarantee the filtration pressure desired. A detailed description of the construction can be found in the Supporting Information.

Electroassisted dead-end filtration was studied at two different pressure effects and electric fields: 10B (low) and 20B (high) and 0.5 and $1 \mathrm{~V} / \mathrm{nm}$, respectively. The results presented in Figure 14 (and Figure S3) suggest that the flow

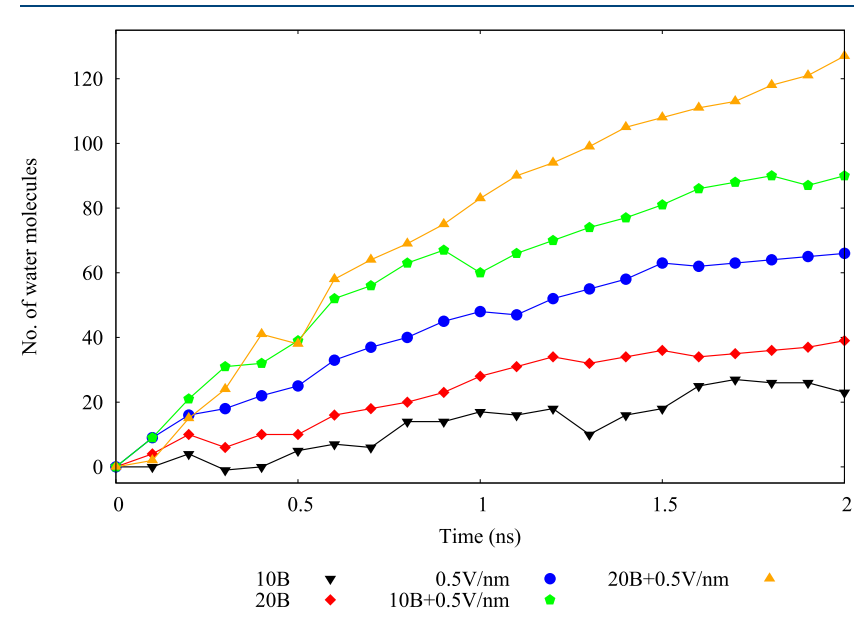

Figure 14. Water flow through the cellulose filter as a function of time at an applied electric field of $0.5 \mathrm{~V} / \mathrm{nm}$ and different pressure effects.

rate of water molecules is extremely low when pressure alone is applied compared to an electric field alone. The cases in which the combined electric fields and pressure effects are applied are worth noting because the flow rates in these systems are visibly higher than those where either an electric field or pressure effect is applied alone. Similar results were obtained when an external electric field of $1.0 \mathrm{~V} / \mathrm{nm}$ was applied to the system (Figure S3).

The flow rates of water molecules, calculated after $0.5 \mathrm{~ns}$ of simulation at different applied electric fields and pressure effects, are shown in Figure 15. It can be observed that the flow rate increases more when an electric field alone is applied than 


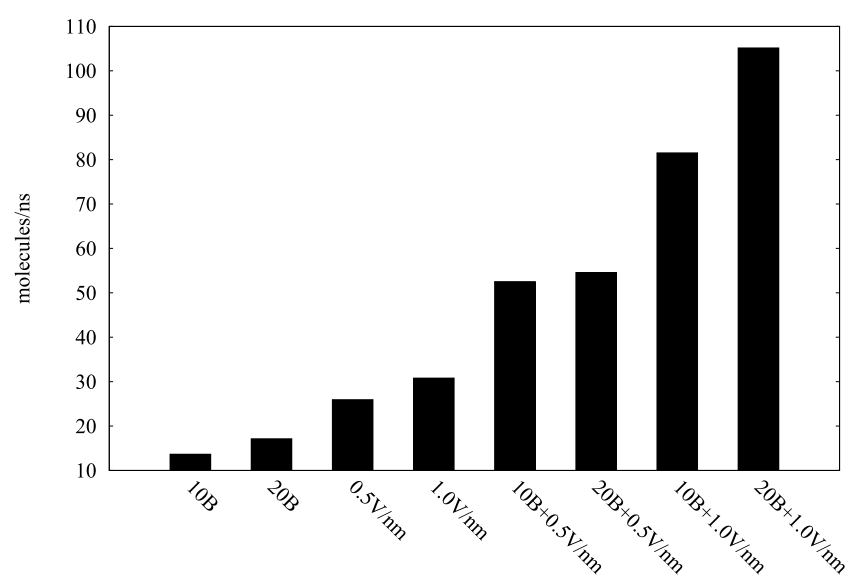

Figure 15. Average flow rate of water molecules at different magnitudes of electric fields and pressures, $0.5 \mathrm{~ns}$ after the onset of filtration simulations.

when only an acceleration field simulating a pressure effect is applied to the system. Similarly, combining an electric field with a pressure effect increases the flow rate significantly in all cases. For instance, the flow rate increases by approximately 1.8 times when an electric field of $1.0 \mathrm{~V} / \mathrm{nm}$ alone is applied as compared to the case when a higher pressure effect (20B) alone is applied but increases by approximately 6 times when a combination is used. Similarly, the flow rate increases as the applied pressure increases. These results suggest that both an electric field and pressure act as driving forces for the movement of water molecules through the filter medium in the filtration process.

It appears that, as the strength of the electric field increases, the movement of cellulose fibrils toward the anode (Figure S4) and sodium ions toward the cathode increases. Simultaneously, more interstitial water molecules are expelled from the interfibrillar space, creating a larger number of "free" water molecules and $\mathrm{Na}^{+}$ions that then move toward the cathode. This bulk of free water molecules, along with the $\mathrm{Na}^{+}$ions, has a lower viscosity ${ }^{87}$ than the TOC suspension ${ }^{88}$ and is hence expelled more efficiently by the combined effect of pressure and electric field.

Although the simulation results follow the same trends as dewatering experiments and were helpful in explaining the observed trends, changes in viscosity of the suspensions due to ohmic heating, which might affect the dewatering rate, could not be simulated due to inherent limitations of the simulation technique used. Furthermore, orientational and interlocking effects of fibrils in simulations were not seen due to the limited simulation time and system size used, although they could be relevant under real conditions.

\section{CONCLUSIONS}

Despite the extensive knowledge of the efficacy an external electric field has on the dewatering phenomenon, studies have been restricted mainly to sludge ${ }^{19-25}$ and clay. ${ }^{26,27}$ In the present study, however, the effectiveness of this filtration technique has been demonstrated in the dewatering of TEMPO-MFC. The insights provided by the experiments and atomistic simulations indicate that a combination of pressure and electric field, i.e., electroassisted filtration, improves the dewatering of TEMPO-MFC.
The dewatering rate was observed to be proportional to the electric field applied. The electrokinetic motion of the particles and the reduced viscosity resulting from thermal effects, phenomena also observed by Weber and Stahl, ${ }^{38}$ and an increase in the amount of free water in the system could be the main reason for enhanced dewatering. Furthermore, the formation of channeled structures due to the aggregation of the fibrils on the anodic mesh, as seen in the experiments, could also contribute positively to the dewatering rate.

MD simulations, performed to provide a more comprehensive understanding of the dewatering mechanism at a molecular level, suggest that an electric field causes an electrophoretic movement of the cellulose fibrils toward the anode: the water that is trapped between the fibrils is thereby left behind in the form of "free" water. This, in turn, is forced out by the applied hydraulic pressure along with the rest of the bulk water. Another benefit of the electrophoretic movement of the fibrils is that it reduces the buildup of a resistant filter cake, as was seen in the experiments. In addition, neglecting the effects of the electrolysis of water molecules and viscosity changes due to an increase in temperature, the results from the simulations indicate that the impact of pressure alone on the movement of fibrils is very limited, whereas that of an electric field is significant.

It should be noted that although the results obtained from the experimental and MD simulations imply similar dewatering trends, they should not be compared quantitatively due to differences in time scale, length scale, and phenomena such as electrolysis and ohmic heating, along with mechanical interlocking between the fibrils, implicit to the application of an electric field in the experiments.

Based on the results presented in this paper, electroassisted filtration shows a huge potential for improving the dewatering of TEMPO-MFC. It should be noted that this study was limited to one type of MFC (TEMPO-MFC), i.e., it was not extended to cover additional types of fibrillated cellulose. The findings nevertheless contribute to unlocking the true potential of electroassisted filtration as a means of dewatering MFC, also observed by Heiskanen et al. ${ }^{31}$ Much remains to be investigated, however, in terms of understanding both the complicated dewatering mechanism and the impact of the process parameters.

\section{ASSOCIATED CONTENT}

\section{Supporting Information}

The Supporting Information is available free of charge at https://pubs.acs.org/doi/10.1021/acs.iecr.1c03749.

Additional experimental results (peaks from ATR-FTIR spectra and temperature increase during electroassisted filtration) and additional results from simulations and a detailed description of the final simulation setup (PDF)

\section{AUTHOR INFORMATION}

\section{Corresponding Author}

Hans Theliander - Department of Chemistry and Chemical Engineering, Chalmers University of Technology, SE-412 96 Gothenburg, Sweden; Wallenberg Wood Science Center, The Royal Institute of Technology, Chalmers University of Technology, Linköping University, SE-100 44 Stockholm, Sweden; (1) orcid.org/0000-0002-2120-6513;

Email: hanst@chalmers.se 


\section{Authors}

Nabin Kumar Karna - Department of Chemistry and Chemical Engineering, Chalmers University of Technology, SE-412 96 Gothenburg, Sweden; Wallenberg Wood Science Center, The Royal Institute of Technology, Chalmers University of Technology, Linköping University, SE-100 44 Stockholm, Sweden; (1) orcid.org/0000-0002-2496-9647

Anna Lidén - Department of Chemistry and Chemical Engineering, Chalmers University of Technology, SE-41296 Gothenburg, Sweden; (1) orcid.org/0000-0002-0169-1398

Jakob Wohlert - Wallenberg Wood Science Center, The Royal Institute of Technology, Chalmers University of Technology, Linköping University, SE-100 44 Stockholm, Sweden; Department of Fibre and Polymer Technology, KTH Royal Institute of Technology, SE-100 44 Stockholm, Sweden; () orcid.org/0000-0001-6732-2571

Complete contact information is available at: https://pubs.acs.org/10.1021/acs.iecr.1c03749

\section{Notes}

The authors declare no competing financial interest.

\section{ACKNOWLEDGMENTS}

The financial aid received from The Swedish Research Council (Vetenskapsrådet) and Knut and Alice Wallenberg Foundation is gratefully acknowledged. This research was partially supported by the Chalmers Centre for Computational Science and Engineering (C3SE) provided by the Swedish National Infrastructure for Computing (SNIC) and the supercomputing infrastructure of the NLHPC (ECM-02) provided by Universidad de Chile, Chile. The authors also acknowledge Ph.D. candidates Roujin Ghaffari, Shirin Naserifar, and Aina Edgren for their assistance with the $\zeta$ potential, ATR-FTIR, and SEM, respectively.

\section{REFERENCES}

(1) Klemm, D.; Kramer, F.; Moritz, S.; Lindström, T.; Ankerfors, M.; Gray, D.; Dorris, A. Nanocelluloses: A New Family of Nature-Based Materials. Angew. Chem., Int. Ed. 2011, 50, 5438-5466.

(2) Belbekhouche, S.; Bras, J.; Siqueira, G.; Chappey, C.; Lebrun, L.; Khelifi, B.; Marais, S.; Dufresne, A. Water sorption behavior and gas barrier properties of cellulose whiskers and microfibrils films. Carbohydr. Polym. 2011, 83, 1740-1748.

(3) Fukuzumi, H.; Tanaka, R.; Saito, T.; Isogai, A. Dispersion stability and aggregation behavior of TEMPO-oxidized cellulose nanofibrils in water as a function of salt addition. Cellulose 2014, 21, 1553-1559.

(4) Rol, F.; Belgacem, M. N.; Gandini, A.; Bras, J. Recent advances in surface-modified cellulose nanofibrils. Prog. Polym. Sci. 2019, 88, 241-264.

(5) Sim, K.; Lee, J.; Lee, H.; Youn, H. J. Flocculation behavior of cellulose nanofibrils under different salt conditions and its impact on network strength and dewatering ability. Cellulose 2015, 22, 36893700.

(6) Abdul Khalil, H. P. S.; Bhat, A. H.; Ireana Yusra, A. F. Green composites from sustainable cellulose nanofibrils: A review. Carbohydr. Polym. 2012, 87, 963-979.

(7) Brodin, F. W.; Gregersen, Ø. W.; Syverud, K. Cellulose nanofibrils: Challenges and possibilities as a paper additive or coating material - A review. Nord. Pulp Pap. Res. J. 2014, 29, 156-166.

(8) Balea, A.; Fuente, E.; Monte, M. C.; Merayo, N.; Campano, C.; Negro, C.; Blanco, A. Industrial Application of Nanocelluloses in Papermaking: A Review of Challenges, Technical Solutions, and Market Perspectives. Molecules 2020, 25, No. 526.
(9) Herrick, F. W.; Casebier, R. L.; Hamilton, J. K.; Sandberg, K. R. In Microfibrillated Cellulose: Morphology and Accessibility, 1983; Vol. 37. https://www.osti.gov/biblio/5039044.

(10) Turbak, A. F.; Snyder, F. W.; Sandberg, K. R. In Microfibrillated Cellulose, A New Cellulose Product: Properties, Uses, and Commercial Potential, 1983; Vol. 37. https://www.osti.gov/biblio/5062478.

(11) Eriksen, Ø.; Syverud, K.; Gregersen, Ø. The use of microfibrillated cellulose produced from kraft pulp as strength enhancer in TMP paper. Nord. Pulp Pap. Res. J. 2008, 23, 299-304.

(12) Pääkkö, M.; Ankerfors, M.; Kosonen, H.; Nykänen, A.; Ahola, S.; Österberg, M.; Ruokolainen, J.; Laine, J.; Larsson, P. T.; Ikkala, O.; Lindström, T. Enzymatic Hydrolysis Combined with Mechanical Shearing and High-Pressure Homogenization for Nanoscale Cellulose Fibrils and Strong Gels. Biomacromolecules 2007, 8, 1934-1941.

(13) Wågberg, L.; Decher, G.; Norgren, M.; Lindström, T.; Ankerfors, M.; Axnäs, K. The Build-Up of Polyelectrolyte Multilayers of Microfibrillated Cellulose and Cationic Polyelectrolytes. Langmuir 2008, 24, 784-795.

(14) Ghanadpour, M.; Carosio, F.; Larsson, P. T.; Wågberg, L. Phosphorylated Cellulose Nanofibrils: A Renewable Nanomaterial for the Preparation of Intrinsically Flame-Retardant Materials. Biomacromolecules 2015, 16, 3399-3410.

(15) Saito, T.; Isogai, A. TEMPO-Mediated Oxidation of Native Cellulose. The Effect of Oxidation Conditions on Chemical and Crystal Structures of the Water-Insoluble Fractions. Biomacromolecules 2004, 5, 1983-1989.

(16) Sinquefield, S.; Ciesielski, P. N.; Li, K.; Gardner, D. J.; Ozcan, S. Nanocellulose Dewatering and Drying: Current State and Future Perspectives. ACS Sustainable Chem. Eng. 2020, 8, 9601-9615.

(17) Peng, Y.; Gardner, D. J.; Han, Y. Drying cellulose nanofibrils: in search of a suitable method. Cellulose 2012, 19, 91-102.

(18) Diniz, J. M. B. F.; Gil, M. H.; Castro, J. A. A. M. Hornification-its origin and interpretation in wood pulps. Wood Sci Technol. 2004, 37, 489-494.

(19) Saveyn, H.; Van der Meeren, P.; Pauwels, G.; Timmerman, R. Bench- and pilot-scale sludge electrodewatering in a diaphragm filter press. Water Sci. Technol. 2006, 54, 53-60.

(20) Olivier, J.; Conrardy, J.-B.; Mahmoud, A.; Vaxelaire, J. Electrodewatering of wastewater sludge: An investigation of the relationship between filtrate flow rate and electric current. Water Res. 2015, 82, 66-77.

(21) Chen, G.; Lai, K. C. K.; Lo, I. M. C. Behavior of Electroosmotic Dewatering of Biological Sludge with Salinity. Sep. Sci. Technol. 2003, 38, 903-915.

(22) Citeau, M.; Larue, O.; Vorobiev, E. Influence of salt, $\mathrm{pH}$ and polyelectrolyte on the pressure electro-dewatering of sewage sludge. Water Res. 2011, 45, 2167-2180.

(23) Lee, J.-K.; Shin, H.-S.; Park, C.-J.; Lee, C.-G.; Lee, J.-E.; Kim, Y.-W. Performance evaluation of electrodewatering system for sewage sludges. Korean J. Chem. Eng. 2002, 19, 41-45.

(24) Mahmoud, A.; Olivier, J.; Vaxelaire, J.; Hoadley, A. F. A. Electro-dewatering of wastewater sludge: Influence of the operating conditions and their interactions effects. Water Res. 2011, 45, 27952810.

(25) Sun, B.; Xin, Y.; Hao, J.; Zhu, X.; Yan, Z. Influence of conductivity on the electro-dewatering of sewage sludge under constant voltage. Sep. Sci. Technol. 2017, 52, 2429-2434.

(26) Shang, J. Q.; Lo, K. Y. Electrokinetic dewatering of a phosphate clay. J. Hazard. Mater. 1997, 55, 117-133.

(27) Vijh, A. K. Electrochemical Aspects of Electroosmotic Dewatering of Clay Suspensions. Drying Technol. 1995, 13, 215-224.

(28) Wetterling, J.; Jonsson, S.; Mattsson, T.; Theliander, H. The Influence of Ionic Strength on the Electroassisted Filtration of Microcrystalline Cellulose. Ind. Eng. Chem. Res. 2017, 56, 1278912798.

(29) Wetterling, J.; Mattsson, T.; Theliander, H. Local filtration properties of microcrystalline cellulose: Influence of an electric field. Chem. Eng. Sci. 2017, 171, 368-378. 
(30) Hubbe, M. A.; Heitmann, J. A. Review of Factors Affecting the Release of Water from Cellulosic Fibers during Paper Manufacture. BioResources 2007, 2, 500-533.

(31) Heiskanen, I.; Backfolk, K.; Kotilainen, A.; Gaidelis, V.; Sidaravicius, J. Process for Treating Microfibrillated Cellulose and Microfibrillated Cellulose Treated According to the Process. US20,140,088,301A1, 2014 (accessed June 3, 2021).

(32) Weber, K.; Stahl, W. Influence of an Electric Field on Filtration in a Filter Press. Chem. Eng. Technol. 2003, 26, 44-48.

(33) Yoshida, H.; Mizuno, H.; Kinjo, T.; Washizu, H.; Barrat, J.-L. Molecular dynamics simulation of electrokinetic flow of an aqueous electrolyte solution in nanochannels. J. Chem. Phys. 2014, 140, No. 214701.

(34) Qiao, R.; Aluru, N. R. Charge Inversion and Flow Reversal in a Nanochannel Electro-osmotic Flow. Phys. Rev. Lett. 2004, 92, No. 198301

(35) Zhang, C.; Lu, P.; Chen, Y. Molecular dynamics simulation of electroosmotic flow in rough nanochannels. Int. Commun. Heat Mass Transfer 2014, 59, 101-105.

(36) Bourg, I. C.; Sposito, G. Molecular dynamics simulations of the electrical double layer on smectite surfaces contacting concentrated mixed electrolyte ( $\mathrm{NaCl}-\mathrm{CaCl} 2)$ solutions. J. Colloid Interface Sci. 2011, 360, 701-715.

(37) Rezaei, M.; Azimian, A. R.; Semiromi, D. T. The surface charge density effect on the electro-osmotic flow in a nanochannel: a molecular dynamics study. Heat Mass Transfer 2015, 51, 661-670.

(38) Weber, K.; Stahl, W. Improvement of filtration kinetics by pressure electrofiltration. Sep. Purif. Technol. 2002, 26, 69-80.

(39) Mahmoud, A.; Olivier, J.; Vaxelaire, J.; Hoadley, A. F. A. Electrical field: A historical review of its application and contributions in wastewater sludge dewatering. Water Res. 2010, 44, 2381-2407.

(40) Sjöström, E. The origin of charge on cellulosic fibers. Nord. Pulp Pap. Res. J. 1989, 4, 90-93.

(41) Moulik, S. P. Physical aspects of electrofiltration. Environ. Sci. Technol. 1971, 5, 771-776.

(42) Wall, S. The history of electrokinetic phenomena. Curr. Opin. Colloid Interface Sci. 2010, 15, 119-124.

(43) Citeau, M.; Loginov, M.; Vorobiev, E. Improvement of sludge electrodewatering by anode flushing. Drying Technol. 2016, 34, 307317.

(44) Lockhart, N. C. Electroosmotic dewatering of clays. I. Influence of voltage. Colloids Surf. 1983, 6, 229-238.

(45) Citeau, M.; Larue, O.; Vorobiev, E. Influence of Filter Cell Configuration and Process Parameters on the Electro-Osmotic Dewatering of Sewage Sludge. Sep. Sci. Technol. 2012, 47, 11-21.

(46) Larue, O.; Vorobiev, E. Sedimentation and water electrolysis effects in electrofiltration of kaolin suspension. AIChE J. 2004, 50, $3120-3133$.

(47) Brodin, F. W.; Theliander, H. Absorbent Materials Based on Kraft Pulp: Preparation and Material Characterization. BioResources 2012, 7, 1666-1683.

(48) Brodin, F. W.; Sonavane, Y.; Theliander, H. Preparation of Absorbent Foam Based on Softwood Kraft Pulp: Advancing from Gram to Kilogram Scale. BioResources 2013, 8, 2099-2117.

(49) Theander, O.; Westerlund, E. A. Studies on dietary fiber. 3. Improved procedures for analysis of dietary fiber. J. Agric. Food Chem. 1986, 34, 330-336.

(50) Wojtasz-Mucha, J.; Hasani, M.; Theliander, H. Hydrothermal pretreatment of wood by mild steam explosion and hot water extraction. Bioresour. Technol. 2017, 241, 120-126.

(51) Mautner, A.; Mayer, F.; Hervy, M.; Lee, K.-Y.; Bismarck, A. Better together: synergy in nanocellulose blends. Philos. Trans. R. Soc., A 2018, 376, No. 20170043.

(52) Saito, T.; Isogai, A. TEMPO-Mediated Oxidation of Native Cellulose. The Effect of Oxidation Conditions on Chemical and Crystal Structures of the Water-Insoluble Fractions. Biomacromolecules 2004, 5, 1983-1989.
(53) Wang, X.; Maloney, T.; Paulapuro, H. Internal Fibrillation in Never-dried and Once-dried Chemical Pulps. Appita J. 2003, 56, 455-459.

(54) Johansson, C.; Theliander, H. Measuring concentration and pressure profiles in deadend filtration. Filtration 2003, 3, 114-120.

(55) Berglund, J.; d'Ortoli, T. A.; Vilaplana, F.; Widmalm, G.; Bergenstråhle-Wohlert, M.; Lawoko, M.; Henriksson, G.; Lindström, M.; Wohlert, J. A molecular dynamics study of the effect of glycosidic linkage type in the hemicellulose backbone on the molecular chain flexibility. Plant J. 2016, 88, 56-70.

(56) Pandey, B.; Grover, A.; Sharma, P. Molecular dynamics simulations revealed structural differences among WRKY domainDNA interaction in barley (Hordeum vulgare). BMC Genomics 2018, 19, No. 132.

(57) Abraham, M. J.; Murtola, T.; Schulz, R.; Páll, S.; Smith, J. C.; Hess, B.; Lindahl, E. GROMACS: High performance molecular simulations through multi-level parallelism from laptops to supercomputers. SoftwareX 2015, 1-2, 19-25.

(58) Essmann, U.; Perera, L.; Berkowitz, M. L.; Darden, T.; Lee, H.; Pedersen, L. G. A smooth particle mesh Ewald method. J. Chem. Phys. 1995, 103, 8577-8593.

(59) English, N. J.; Waldron, C. J. Perspectives on external electric fields in molecular simulation: progress, prospects and challenges. Phys. Chem. Chem. Phys. 2015, 17, 12407-12440.

(60) Bussi, G.; Donadio, D.; Parrinello, M. Canonical sampling through velocity rescaling. J. Chem. Phys. 2007, 126, No. 014101.

(61) Basconi, J. E.; Shirts, M. R. Effects of Temperature Control Algorithms on Transport Properties and Kinetics in Molecular Dynamics Simulations. J. Chem. Theory Comput. 2013, 9, 2887-2899.

(62) Berendsen, H. J. C.; Grigera, J. R.; Straatsma, T. P. The missing term in effective pair potentials. J. Phys. Chem. A. 1987, 91, 62696271.

(63) Schmidt, J. R.; Roberts, S. T.; Loparo, J. J.; Tokmakoff, A.; Fayer, M. D.; Skinner, J. L. Are water simulation models consistent with steady-state and ultrafast vibrational spectroscopy experiments? Chem. Phys. 2007, 341, 143-157.

(64) Vega, C.; de Miguel, E. Surface tension of the most popular models of water by using the test-area simulation method. J. Chem. Phys. 2007, 126, No. 154707.

(65) Nishiyama, Y.; Langan, P.; Chanzy, H. Crystal Structure and Hydrogen-Bonding System in Cellulose $\mathrm{I} \beta$ from Synchrotron X-ray and Neutron Fiber Diffraction. J. Am. Chem. Soc. 2002, 124, 90749082.

(66) Paajanen, A.; Sonavane, Y.; Ignasiak, D.; Ketoja, J. A.; Maloney, T.; Paavilainen, S. Atomistic molecular dynamics simulations on the interaction of TEMPO-oxidized cellulose nanofibrils in water. Cellulose 2016, 23, 3449-3462.

(67) Karna, N. K.; Wohlert, J.; Lidén, A.; Mattsson, T.; Theliander, $\mathrm{H}$. Wettability of cellulose surfaces under the influence of an external electric field. J. Colloid Interface Sci. 2021, 589, 347-355.

(68) Hornak, V.; Abel, R.; Okur, A.; Strockbine, B.; Roitberg, A.; Simmerling, C. Comparison of multiple Amber force fields and development of improved protein backbone parameters. Proteins: Struct., Funct., Bioinf. 2006, 65, 712-725.

(69) Huang, J.; Rauscher, S.; Nawrocki, G.; Ran, T.; Feig, M.; de Groot, B. L.; Grubmüller, H.; MacKerell, A. D. CHARMM36m: an improved force field for folded and intrinsically disordered proteins. Nat. Methods 2017, 14, 71-73.

(70) Pol-Fachin, L.; Rusu, V. H.; Verli, H.; Lins, R. D. GROMOS 53A6GLYC, an Improved GROMOS Force Field for HexopyranoseBased Carbohydrates. J. Chem. Theory Comput. 2012, 8, 4681-4690.

(71) Kirschner, K. N.; Yongye, A. B.; Tschampel, S. M.; GonzálezOuteiriño, J.; Daniels, C. R.; Foley, B. L.; Woods, R. J. GLYCAM06: A generalizable biomolecular force field. Carbohydrates. J. Comput. Chem. 2008, 29, 622-655.

(72) Yuriev, E.; Ramsland, P. A. Carbohydrates in Cyberspace. Front. Immunol. 2015, 6, No. 300

(73) Matthews, J. F.; Beckham, G. T.; Bergenstråhle-Wohlert, M.; Brady, J. W.; Himmel, M. E.; Crowley, M. F. Comparison of Cellulose 
I $\beta$ Simulations with Three Carbohydrate Force Fields. J. Chem. Theory Comput. 2012, 8, 735-748.

(74) Sauter, J.; Grafmüller, A. Solution Properties of Hemicellulose Polysaccharides with Four Common Carbohydrate Force Fields. J. Chem. Theory Comput. 2015, 11, 1765-1774.

(75) Yui, T.; Nishimura, S.; Akiba, S.; Hayashi, S. Swelling behavior of the cellulose $\mathrm{I} \beta$ crystal models by molecular dynamics. Carbohydr. Res. 2006, 341, 2521-2530.

(76) Onyianta, A.; Dorris, M.; Williams, R. Aqueous morpholine pre-treatment in cellulose nanofibril (CNF) production: comparison with carboxymethylation and TEMPO oxidisation pre-treatment methods. Cellulose 2018, 25, 1047-1064.

(77) Moser, C.; Henriksson, G.; Lindström, M. E. Specific Surface Area Increase during Cellulose Nanofiber Manufacturing Related to Energy Input. BioResources 2016, 11, 7124-7132.

(78) Ketola, A. E.; Leppänen, M.; Turpeinen, T.; Papponen, P.; Strand, A.; Sundberg, A.; Arstila, K.; Retulainen, E. Cellulose nanofibrils prepared by gentle drying methods reveal the limits of helium ion microscopy imaging. RSC Adv. 2019, 9, 15668-15677.

(79) Amini, E.; Tajvidi, M.; Bousfield, D. W.; Gardner, D. J.; Shaler, S. M. Dewatering Behavior of a Wood-Cellulose Nanofibril Particulate System. Sci. Rep. 2019, 9, No. 14584.

(80) Olivier, J.; Mahmoud, A.; Vaxelaire, J.; Conrardy, J.-B.; Citeau, M.; Vorobiev, E. Electro-Dewatering of Anaerobically Digested and Activated Sludges: An Energy Aspect Analysis. Drying Technol. 2014, 32, 1091-1103.

(81) Gözke, G.; Kirschhöfer, F.; Heissler, S.; Trutnau, M.; BrennerWeiss, G.; Ondruschka, J.; Obst, U.; Posten, C. Filtration kinetics of chitosan separation by electrofiltration. Biotechnol. J. 2012, 7, 262274.

(82) Bordel, D.; Putaux, J.-L.; Heux, L. Orientation of Native Cellulose in an Electric Field. Langmuir 2006, 22, 4899-4901.

(83) Kim, H. C.; Kim, J. W.; Zhai, L.; Kim, J. Strong and tough long cellulose fibers made by aligning cellulose nanofibers under magnetic and electric fields. Cellulose 2019, 26, 5821-5829.

(84) Wise, H. G.; Takana, H.; Ohuchi, F.; Dichiara, A. B. FieldAssisted Alignment of Cellulose Nanofibrils in a Continuous FlowFocusing System. ACS Appl. Mater. Interfaces 2020, 12, 2856828575.

(85) Wetterling, J.; Sahlin, K.; Mattsson, T.; Westman, G.; Theliander, H. Electroosmotic dewatering of cellulose nanocrystals. Cellulose 2018, 25, 2321-2329.

(86) Welch, D. A.; Mehdi, B. L.; Hatchell, H. J.; Faller, R.; Evans, J. E.; Browning, N. D. Using molecular dynamics to quantify the electrical double layer and examine the potential for its direct observation in the in-situ TEM. Adv. Struct. Chem. Imaging 2015, 1, No. 1.

(87) Aleksandrov, A. A.; Dzhuraeva, E. V.; Utenkov, V. F. Viscosity of aqueous solutions of sodium chloride. High Temp. 2012, 50, 354358.

(88) Moberg, T.; Sahlin, K.; Yao, K.; Geng, S.; Westman, G.; Zhou, Q.; Oksman, K.; Rigdahl, M. Rheological properties of nanocellulose suspensions: effects of fibril/particle dimensions and surface characteristics. Cellulose 2017, 24, 2499-2510. 